\title{
The Vibrant Soundbridge
}

\section{Ashutosh G Pusalkar}

Emeritus Professor, Padmashree Dr DY Patil Medical College, Honorary Consultant, Lilavati Hospital and Medical Research Center, Mumbai, Maharashtra, India

Correspondence: Ashutosh G Pusalkar, Om Apartments, 8th Floor, Opposite Balmohan School, Shivaji Park, Dadar (W) Mumbai-400028, Maharashtra, India

\section{Abstract}

Till about 15 years ago, the only choice of hearing improvement for moderate sensorineural hearing loss with severe speech discrimination defect was a hearing aid. It was only after Mr. Geoff Ball, an electronic engineer who was suffering from a similar defect, started thinking of an alternative to the conventional hearing aid that the Vibrant Soundbridge came into existence, and with the passage of time the indications for the use of the same have increased.

Keywords: Vibrant sound bridge, hearing loss.

\section{HISTORICAL REVIEW}

The vibrant soundbridge was invented by Geoff Ball, who was a bilateral soundbridge user. The other landmarks in the history of this device are:

- 1996: 1st patient implanted by U Fisch

- 1998: CE-mark (Europe)

- 2000: FDA approval (USA)

- 2003: Foundation of vibrant MED-EL hearing technology.

\section{THE DEVICE}

It consists of 2 parts:

- The audio processor or AP
- The vibrating ossicular prosthesis or VORP, with its active part known as the floating mass transducer (FMT) (Figs 1A to 2).

The FMT is an electromagnetic transducer. It works on the principle of electromagnetic induction. It requires only one point of fixation (the ossicles or the round window). The FMT reproduces and augments the natural movement of the ossicular chain. The FMT is attached to the long process of incus with a titanium clip. It should be in close contact with and parallel to the stapes.

\section{COMPARISON WITH A HEARING AID}

Unlike, the hearing aid that provides only an 'acoustic amplification', the vibrant soundbridge provides a 'direct
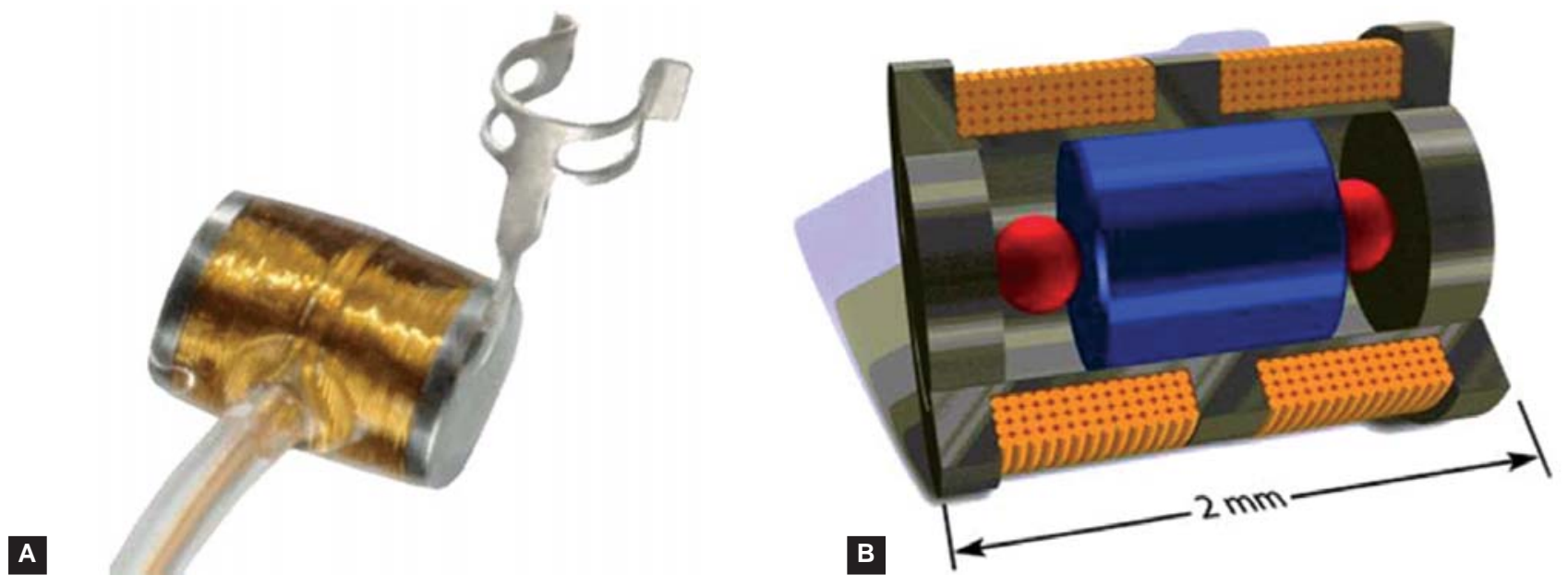

Figs $1 \mathrm{~A}$ and $\mathrm{B}$ : The floating mass transducer 


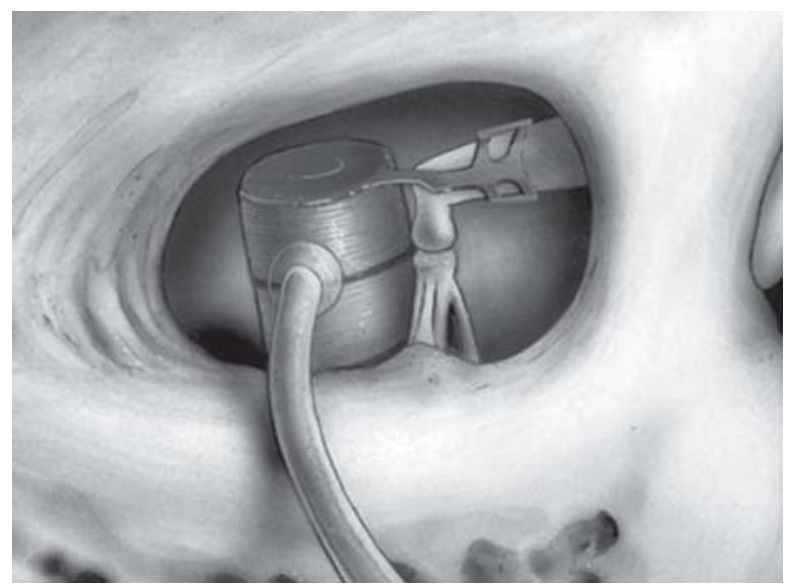

Fig. 2: Alignment of the floating mass transducer with respect to the ossicular chain
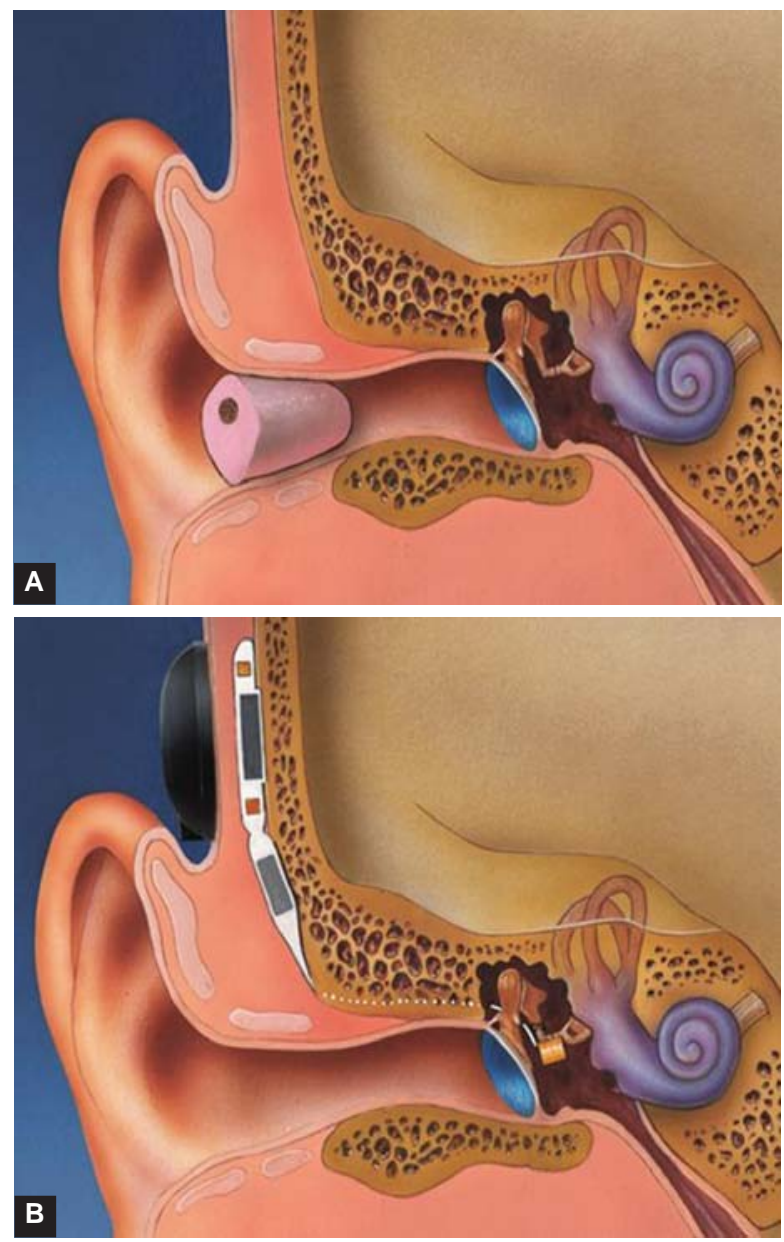

Figs 3A and B: Differences between acoustic amplification (A) and direct drive $(\mathrm{B})$

drive' for the sound waves (Figs $3 \mathrm{~A}$ and $\mathrm{B}$ ), which have the following advantages:

- Elimination of the occlusion effect

- Improved sound quality of own voice
- Increased naturalness of sound quality

- Elimination of feedback

- Easily hidden (covered by hair)

- Improved sound quality of own voice (no occlusion effect)

- High-frequencies can be amplified without creating feedback.

\section{TECHNIQUES}

- Round window vibroplasty (Fig. 4):

- Attachment of FMT onto the RW-membrane bypassing the middle ear.

- TORP/PORP vibroplasty (Figs 5 and 6):

- FMT together with passive ossicular prosthesis used for the reconstruction of the ossicular chain in the middle ear.

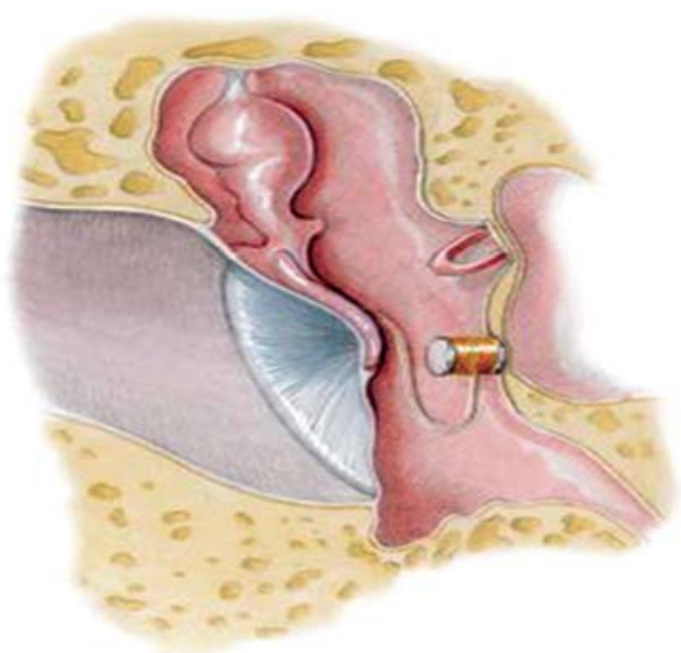

Fig. 4: Round window vibroplasty

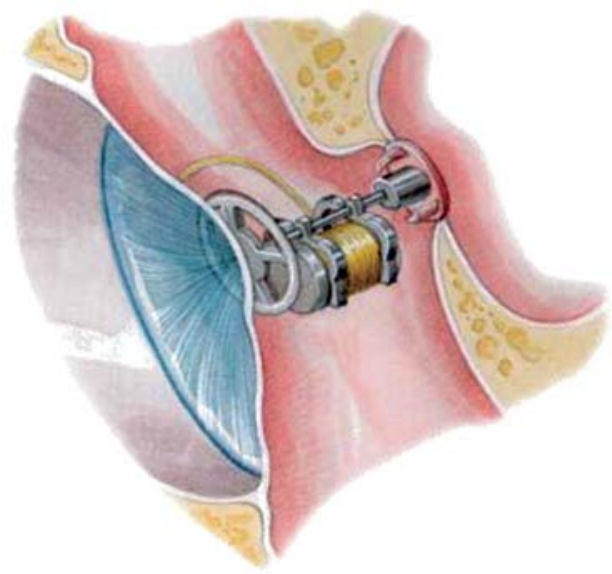

Fig. 5: TORP vibroplasty 


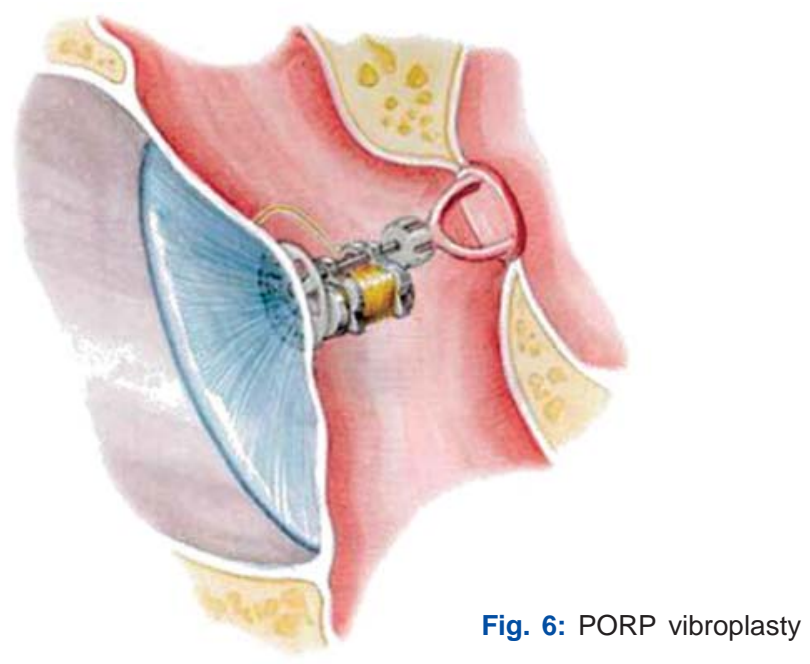

Selection Criteria for the Vibrant Soundbridge ${ }^{\circledR}$

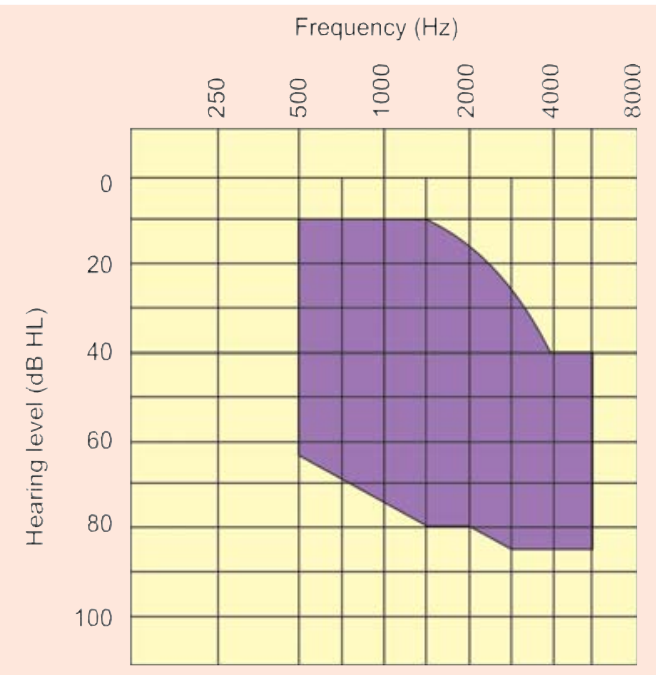

Fig. 7: Sensorineural hearing loss

\section{Sensorineural hearing loss (Fig. 7)}

- Air-conduction thresholds at or within the shaded region

- Normal middle ear function as shown by audiometric thresholds, tympanometry and acoustic reflexes

- Speech understanding of at least $50 \%$ on an open setword test

- At the most comfortable listening level using head phones, or

- At 65 dB SPL in the free field using hearing aid (s)

- Stable hearing loss. Patient should be experienced with hearing aids

- No skin conditions preventing attachment of the audio processor

- Realistic expectations

- Absence of retrocochlear and central auditory disorders

- 18 years of age or older

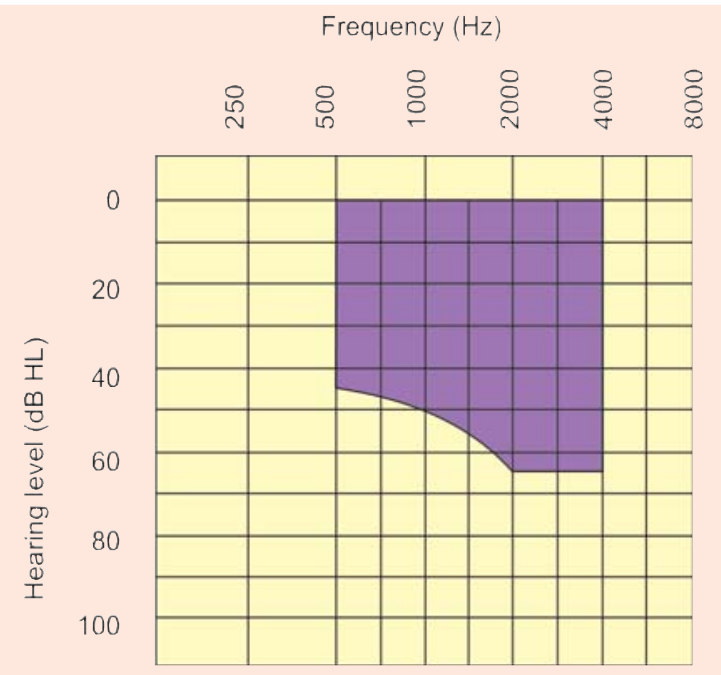

Fig. 8: Conductive and mixed hearing loss

\section{Conductive and mixed hearing loss (Fig. 8)}

- Bone-conduction thresholds at or within the shaded region

- Adequate middle ear space

- Absence of active middle ear infection and/or chronic fluid in the ear

- Stable bone conduction thresholds

- No skin conditions preventing attachment of the audio processor

- Realistic expectations

- Absence of retrocochlear and central auditory disorders

- 18 years of age or older 


\section{INTRODUCTION}

The vibrant soundbridge (VSB) is an active middle ear implant for persons with sensorineural, conductive or mixed hearing losses. The VSB consists of an external part, the audio processor (AP) and an implanted part, the vibrating ossicular prosthesis (VORP). The AP is worn on the head and contains a microphone, a digital signal processor and a battery. The VORP consists of a receiver/stimulator, a conductor link, and a transducer. Information from the AP is sent to the VORP so that the transducer [the floating mass transducer (FMT)] vibrates in a controlled manner; specific to each patient's hearing needs. The FMT is 2.3 $\mathrm{mm}$ in length, $1.8 \mathrm{~mm}$ in diameter and weights about 25 $\mathrm{mg}$. The conductor link has a diameter of $0.6 \mathrm{~mm}$.

The surgery performed is called vibroplasty (Figs 9 and 10). Vibroplasty is the treatment of hearing loss by a vibratory stimulation of the ossicular chain in the middle ear. When the FMT is in proximity to a vibratory structure of the middle ear, it vibrates the structure and stimulates the auditory system.

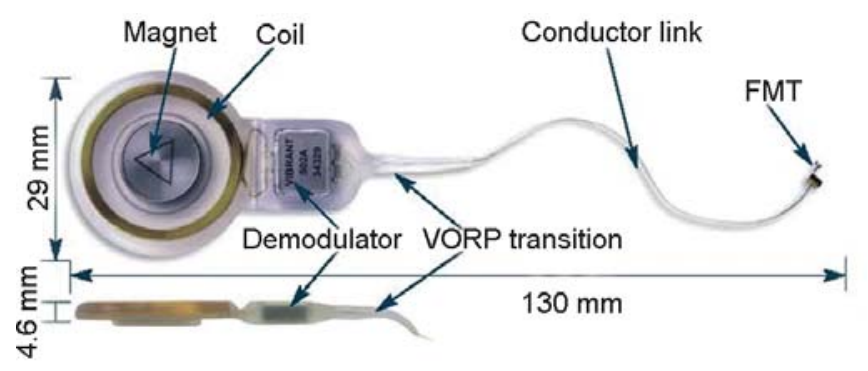

Fig. 9: Parts of the vibrant sound bridge

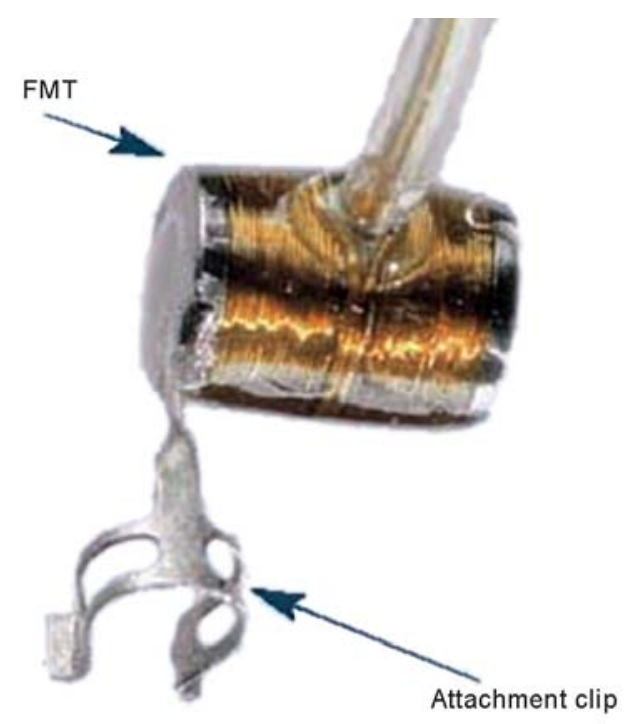

Fig. 10: The floating mass transducer with its attachment clips
Selection of the patient for implantation requires the surgeon and the audiologist to work together. A detailed audiological and medical evaluation is performed and reviewed. Before surgery, patients are counselled about the risks and benefits of VSB implantation. Success is optimal, when the patient is well-selected and has realistic expectations.

\section{VORP TEMPLATE (FIG. 11)}

The VORP template, made of silicone elastomer, has three functions. The first is to determine optimum implant placement on the mastoid before incising the skin. An outline may be drawn to mark this site. The second is to outline the exact size of the placement before drilling. The third is to verify the size of the placement before placing and suturing the VORP to the skull.

\section{CRIMPING FORCEPS}

The forming forceps, made of stainless steel, is used to crimp the FMT clip around the incus. Other otologic forceps (such as stapes wire crimpers or piston closing forceps) can also be used to form the FMT attachment.

\section{THE SURGICAL PROCEDURE}

Surgical placement of the VSB is a very simple procedure that may be performed by any otologist with a standard knowledge of middle ear surgery.

\section{Incision}

The VORP template is placed on the skin with its anterior edge at the postauricular sulcus just behind the ear, and angled approximately 45 degrees posterosuperiorly. The VORP should not lie under the auricle. A marking pen is used to trace the outer perimeter of the template on the scalp.

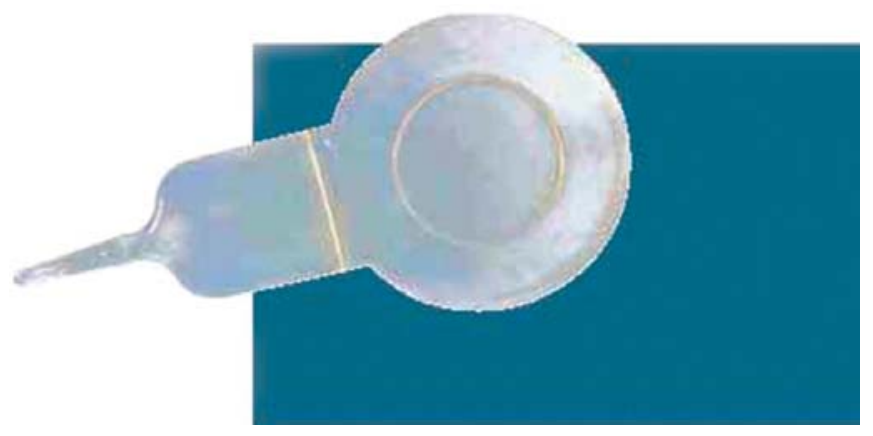

Fig. 11: The VORP template 
The incision is marked at least $2 \mathrm{~cm}$ from the edge of the template to minimize the risk of device extrusion and postoperative infection. The incision only needs to be large enough to perform the mastoidectomy, drill the seat for the demodulator portion of the VORP, and suture it to the bone.

\section{The 'Facial Recess' Route}

A simple/cortical mastoidectomy is performed just to the point that the short process of the incus is visible. The posterior tympanotomy is not performed at this time to limit bone dust from entering the middle ear. When exposing the antrum, care must be taken to avoid contact of the drill with the incus.

Caution: It is advisable to use only a diamond burr when drilling near the facial nerve and the ossicles.

The mastoidectomy may need to be extended slightly posteriorly and inferiorly to allow better visualization of the long process of the incus through the facial recess later in the procedure, leaving a bony overhang superiorly and inferiorly.

\section{The 'Device-seat' and 'Tie-down' Holes}

The primary objective of creating the device seat is to allow the pre-bent transition of the conductor link to slope deeply into the mastoid cavity so that the conductor link is as medial to the skull surface as possible. The device seat also provides a secure and stable position for the VORP.

The mark on the skull is located and the VORP template is then positioned on the skull surface. The position of the template should be approximately at an angle of 45 degrees as described earlier and the transition, approximately $3 \mathrm{~mm}$ from the demodulator, should lie on the posterior edge of the mastoid cavity. Positioning the transition is critical to device placement, and therefore, the final position of the magnet may move slightly anterior or posterior depending upon the size of the mastoid cavity.

Instead of drilling a channel between the seat for the demodulator and the mastoid cavity, a bony bridge may be created. By opening this bridge on the superior side, the VORP transition can be easily slid under the bridge, thus giving more protection. The demodulator should also be fixed with sutures. It is important to ensure that there are no sharp edges from the channel or the bridge and that the midpoint of the transition lies on the posterior edge of the mastoid cavity. The VORP template is positioned in the seat to verify the size and depth of the channel.

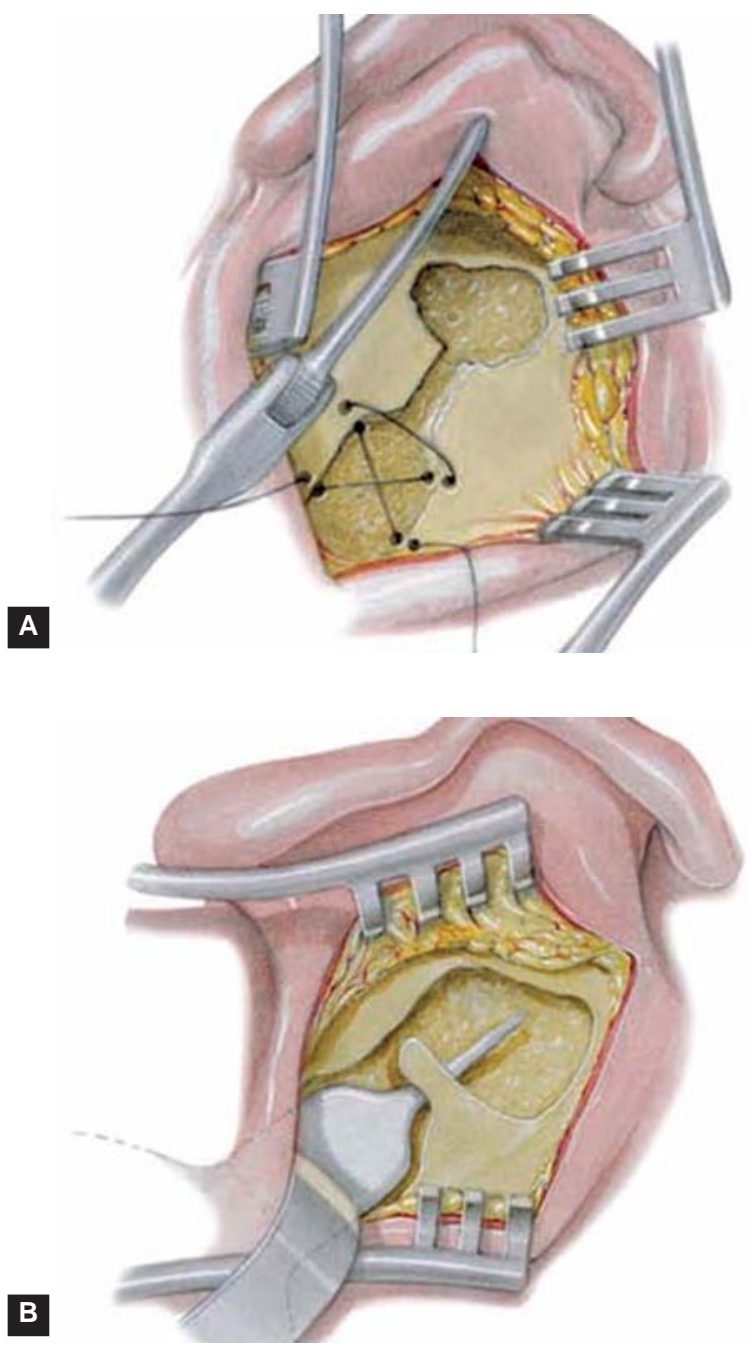

Figs $12 \mathrm{~A}$ and $\mathrm{B}$ : Fixing the VORP

Based on surgical preference, a magnet seat also may be drilled (the magnet may be recessed $1.5 \mathrm{~mm}$ ) or the receiving coil and mag net portion of the VORP may be placed under a periosteal pocket.

Tie-down holes are created on opposing sides of the seat to fix the demodulator. The tie-down holes have to be drilled so that the VORP lies flat when sutured and the VORP transition angles down towards the mastoid cavity (Figs 12A and B).

\section{Routes to the Middle Ear}

- The facial recess route (Fig. 13):

A posterior tympanotomy is created through the facial recess. Care must be taken to avoid the drill contacting middle ear structures. 


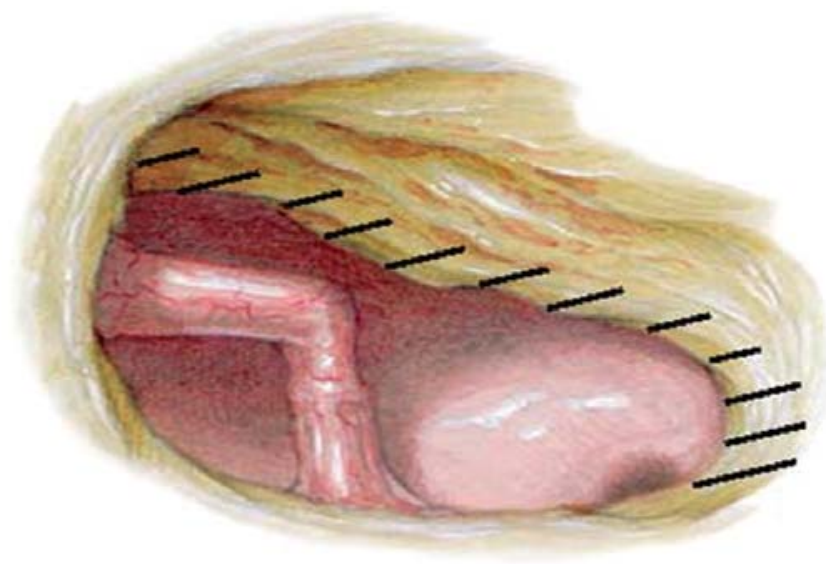

Fig. 13: The facial recess route

Caution: Use only a diamond burr when drilling near the ossicles.

The facial nerve is identified leaving a thin shelf of bone to cover it. The posterior tympanotomy is enlarged to visualize the ossicular chain and extended inferiorly so that the FMT and the forming forceps may be introduced.

A 2.5 to $3.0 \mathrm{~mm}$ drill burr, representing the size of the FMT, should be able to pass through the tympanotomy. Care should be taken to preserve the chorda tympani nerve, if possible, while still allowing adequate space for drilling.

The buttress between the posterior tympanotomy and the opening of the antrum should be preserved, to avoid damage to the ligament attached to the short process of the incus. The middle ear is then irrigated to remove any residual bone dust.

- The transmeatal route (Fig. 14).

The tympanomeatal flap is elevated to visualize the middle ear space.

After identification of the chorda tympani and the annulus, a groove is drilled in the inferior wall of the ear canal. The groove should be 0.5 to $1.0 \mathrm{~mm}$ wide and $2 \mathrm{~mm}$ deep. It is safer to drill away from the middle ear to avoid damaging the ossicles. A channel is dissected between the mastoid cavity and the posterior canal wall, allowing placement of the conductor link during FMT installation.

\section{Fixation of Demodulator}

The VORP is placed over the surgical site so that the magnet protrusion is towards the skull, with the triangle shape on the magnet facing up (Fig. 15). Using a nonresorbable monofilament suture, the demodulator is fixed in place so that it angles down towards the mastoid cavity. The knot is

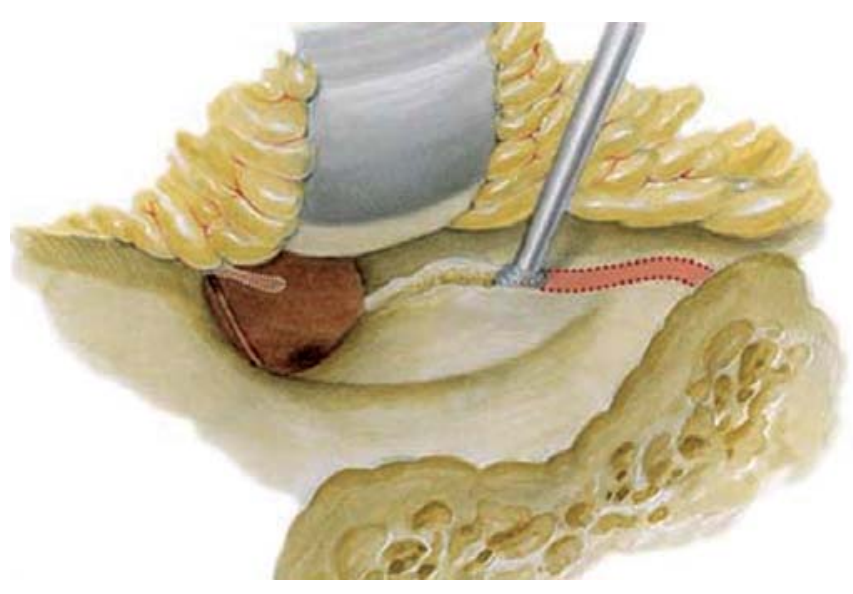

Fig. 14: The transmeatal route

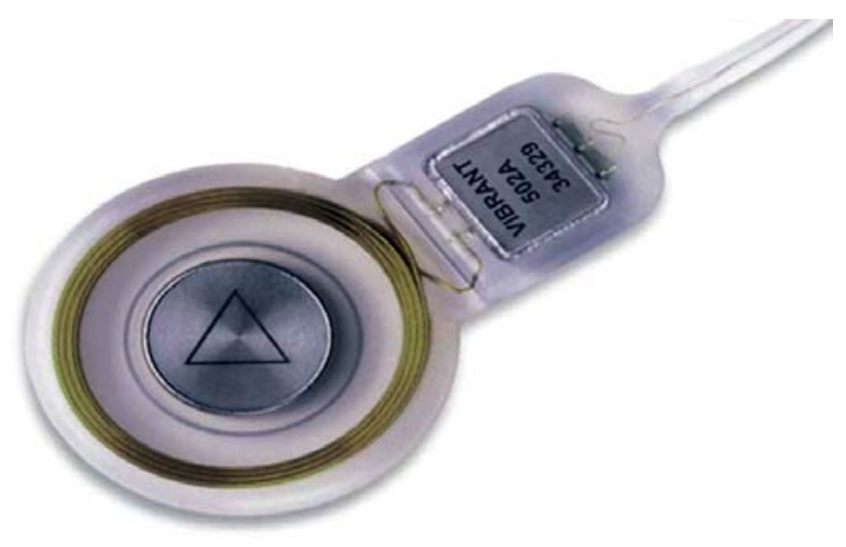

Fig. 15: Arrangement of the VORP with the triangle shape on the magnet facing upwards

retracted into the suture hole. The suture is centered over the demodulator and care should be taken that it does not cross the joint between the demodulator and receiving coil nor that between the transition to the conductor link. Avoid suturing over the receiving coil and magnet.

It is crucial to correctly position the conductor link to avoid an implant failure. When placing the conductor link, make sure that the lead is not bent.

\section{FMT Placement in Incus Vibroplasty}

The FMT is visualized clip under the operating microscope. The clip is carefully opened by sliding a straight needle through the clip opening until the approximate diameter of the long process of the incus is achieved (about $0.5 \mathrm{~mm}$ ).

Pre-bend a small curve in the conductor link a few millimeters from the FMT, so that it does not impede movement of the FMT when in it is final position. 
With the help of a smooth alligator forceps or a suction tip, the FMT is advanced into the middle ear. Avoid grasping the FMT at its junction to the wire. When the clip is in position over the long process of the incus, it is gently pushed onto the incus with a suction tip or right-angled hook. The clip should be as far superior as possible on the incus, and the axis of the FMT should be parallel to the axis of movement of the stapes.

\section{Opening the FMT Clip with a Straight Needle} (Fig. 16)

The FMT must be in close contact with the incudostapedial joint and must not contact the promontory, tympanic membrane, or pyramidal eminence.

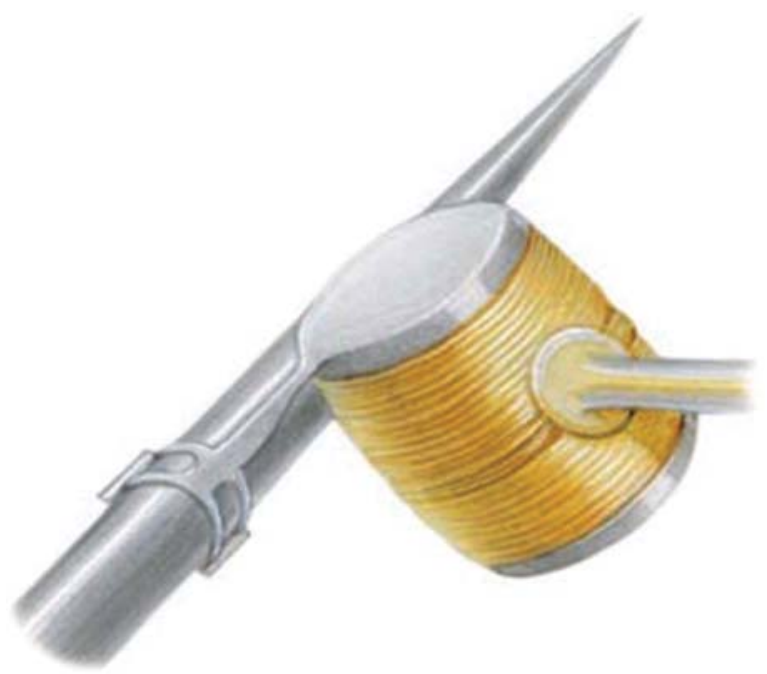

Fig. 16: Opening the FMT clip with a straight needle

The FMT clip is secured in position using the crimping forceps or other otologic forceps (such as stapes wire crimpers or piston-closing forceps) (Figs 17A and B).

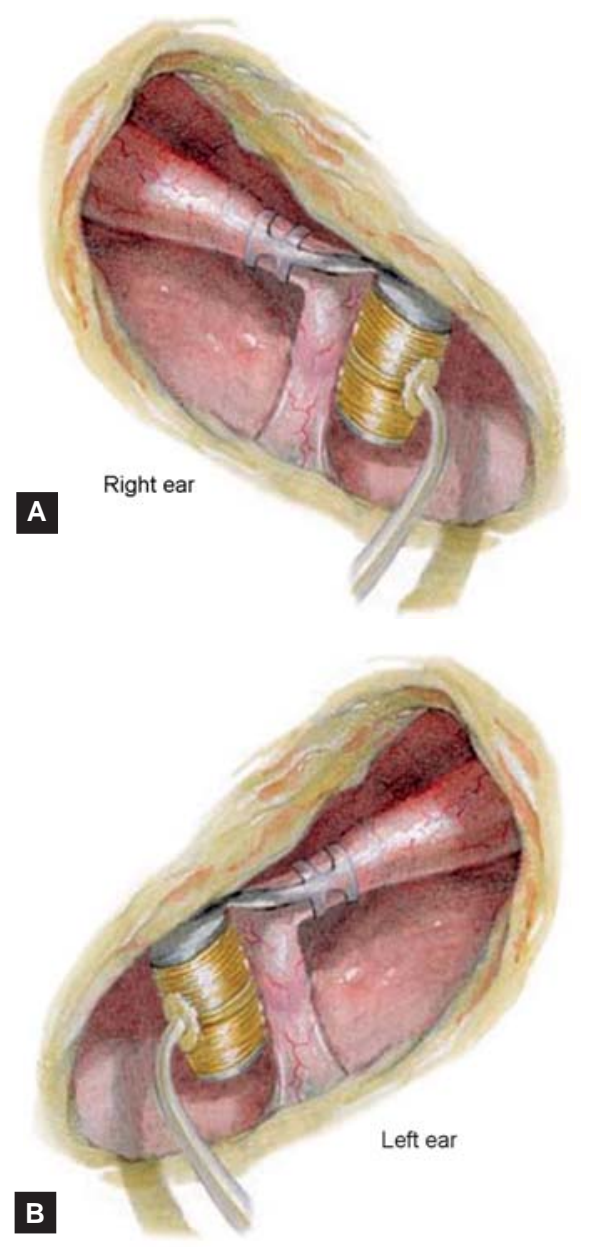

Figs 17A and B: Accurate placement of the FMT in close contact with the Incudo-stapedial joint, but not touching the promontory, tympanic membrane or pyramidal eminence

\section{ACKNOWLEDGMENT}

Images and Inputs from MED-EL Medical Electronics.

\section{REFERENCE}

Refer to the Website - http://www.vibrant-medel.com (Courtesy: MED-EL Medical Electronics). 